Article

\title{
One Pot Synthesis of Pt/Graphene Composite Using Polyamidoamine/Chitosan as a Template and Its Electrocatalysis for Methanol Oxidation
}

\author{
Yanli Wang ${ }^{1}$, Zhongshui Li ${ }^{1,2}$, Shuhong $X u^{1}$, Fengling Lei ${ }^{1}$ and Shen Lin ${ }^{1,2, *}$ \\ 1 College of Chemistry \& Chemical Engineering, Fujian Normal University, Fuzhou 350007, China; \\ yanliwang408@gmail.com (Y.W.); zsli@fjnu.edu.cn (Z.L.); xushuhongxu@gmail.com (S.X.); \\ fenglinglei408@gmail.com (F.L.) \\ 2 Fujian Key Laboratory of Polymer Materials, Fujian Normal University, Fuzhou 350007, China \\ * Correspondence: shenlin@fjnu.edu.cn; Tel./Fax: +86-591-2286-7399
}

Academic Editors: Vincenzo Baglio and David Sebastián

Received: 17 August 2016; Accepted: 19 October 2016; Published: 24 October 2016

\begin{abstract}
A one-pot hydrothermal strategy was used to synthesize Pt/GNs (PAMAM) \& Pt/GNs (CS) composites. Pt nanoparticles are deposited onto graphene sheets (GNs) via synchronous reduction of $\mathrm{K}_{2} \mathrm{PtCl}_{4}$ and graphene oxide (GO) under hydrothermal conditons without additional reducing agent. During the synthesis process, polyamidoamine (PAMAM) or chitosan (CS) was used as a template respectively to obtain shape controlled Pt particles on the surface of GNs, leading to the formation of flower-like Pt nanoclusters for Pt/GNs (PAMAM) and uniform spherical Pt nanoparticles for $\mathrm{Pt} / \mathrm{GNs}$ (CS). PAMAM and CS are simultaneously served as intrinsic reducing agents to accelerate reduction process; ensuring excellent electrical conductivity of the composites. Electrochemical tests show that Pt/GNs (PAMAM) and Pt/GNs (CS) have much higher electrocatalytic activity and better stability toward methanol oxidation reaction (MOR) in comparison with counterpart Pt/GNs and the commercially available $20 \% \mathrm{Pt} / \mathrm{C}$ catalyst $(\mathrm{Pt} / \mathrm{C}$ ) due to their better dispersion of $\mathrm{Pt}$ particles, stronger interaction between $\mathrm{Pt}$ and substrate materials, and better electron transfer capability.
\end{abstract}

Keywords: platinum; polyamidoamine; chitosan; graphene; methanol oxidation

\section{Introduction}

Hydrothermal synthesis method is widely used to synthesize composite materials with excellent properties. Boppella et al. [1] reported the formation of oriented $\mathrm{ZnO}$ structures with tunable percentage of exposed polar facets via a simple hydrothermal route in aqueous base environment. Yu et al. [2] demonstrated unique hollow Pt-ZnO nanocomposite microspheres with hierarchical structure under mild solvothermal conditions. Especially, this method has an advantage for the synthesis of graphene-based nanomaterials due to the possible synchronous reduction of graphene oxide and the corresponding metal precursors [3,4]. Lei et al. [5] have reported one-pot hydrothermal synthesis of an efficient anodic electro-photo catalyst $\mathrm{Pt} / \mathrm{SnO}_{2} / \mathrm{GNs}$ (EDTA) for direct methanol fuel cell (DMFCs) applications. Li et al. [6] developed a facile hydrothermal approach to efficiently synthesize Pt-NCs/rGO composites with high shape selectivity and enhanced catalytic activity for MOR. Yun et al. [7] reported the in situ hydrothermal synthesis of 3D macroporous rGO aerogels/palladium nanoparticle hybrids for electrocatalytic applications. In these reports, they emphasized that the shapes, assembly or dispersion of as-prepared nanoparticles by hydrothermal synthesis method can significantly impact their performance. However, hydrothermal reaction is a "covert operation" and unable to intervene in the reaction process. Therefore, in order to effectively control the micro structure of the products, the raw materials must be strictly selected and the reasonable chemical reactions process needs to be predetermined. 
Polyamidoamine (PAMAM) is one of the most popular dendrimers with a near-spherical structure $[8,9]$. It contains rich cavities within molecules and has a large number of active functional groups on the surface of molecules, which makes it able to graft other ions, molecules or particles on the core, peripheral or embedded cavity by electrostatic interaction and covalent coordination $[10,11]$. Maiyalagan, T. [9] has anchored PAMAM on functionalized carbon nanofibers (CNF) to facilitate the controlled dispersion of Pt-Ru nanoparticles which are used to catalyze methanol oxidation. Chitosan (CS) is an abundant linear polymer, in which there exist a large number of hydroxyls and aminos in polymer chain segments [12-14]. Especially, its $-\mathrm{NH}_{2}$ groups can be protonated in acidic medium, causing them to have a positive charge. The positive protonated amines and the rich hydroxyl in chitosan can act as the mooring point and steric hindrance agent of metal nanoparticles $[15,16]$. Li et al. [17] have assembled worm-like Pt nanoparticles on $\mathrm{PW}_{12}$-GNs support using CS as a shape directing agent for catalyzing methanol oxidation. Thus, it can be reasonable to deduce that the unique structures of dendritic and linear macromolecule above can be used as the agent for controlling $\mathrm{Pt}$ nanoparticles shape and dispersion under hydrothermal conditions.

In this case, a one-pot hydrothermal method was used to synthesize Pt/graphene composites $\mathrm{Pt} / \mathrm{GNs}$ (PAMAM) and Pt/GNs (CS) without additional reducing agent. The fourth generation amine-terminated polyamidoamine dendrimers (PAMAM) and chitosan (CS) not only act as templates to control the morphology of Pt particles but also serve as internal reductants to accelerate reduction reaction, which effectively makes up the "covert operation" shortcomings of hydrothermal reaction to present a new paradigm for the synthesis of graphene based nano-materials with desired morphology. As-synthesized composites show remarkably higher electrocatalytic activity and enhanced resistance to CO poisoning compared with counterpart $\mathrm{Pt} / \mathrm{GNs}$ and commercially available $20 \% \mathrm{Pt} / \mathrm{C}$ catalyst $(\mathrm{Pt} / \mathrm{C})$. Especially, as-synthesized composites show better stability toward methanol oxidation reaction (MOR), which is helpful to overcome the fast decay in catalytic reaction process for Pt-based catalysts.

\section{Results and Discussion}

\subsection{Characterization}

X-ray photoelectron spectroscopy (XPS) of Pt/GNs, Pt/GNs (CS) and Pt/GNs (PAMAM) are shown in Figure 1. The C1s spectra show that carbon elements in complex exist in three kinds of chemical bonds which are mainly in the form of $\mathrm{C}-\mathrm{C}, \mathrm{C}-\mathrm{O} / \mathrm{C}-\mathrm{N}$ and $-\mathrm{CONH}$ [18]. It is calculated that the percentages of the above three kinds of carbon functional groups are $43.24 \%, 15.82 \%, 40.94 \%$ for Pt/GNs (PAMAM) and 43.21\%, 18.81\%, 37.98\% for Pt/GNs (CS), respectively. Correspondingly, they are $60.32 \%, 17.39 \%, 22.29 \%$ for Pt/GNs, respectively. Evidently, the $\mathrm{C}-\mathrm{O} / \mathrm{C}-\mathrm{N}$ components in the three complexes are drastically decreased in comparison with pristine GO [19], which indicates that $\mathrm{GO}$ was converted into graphene sheets (GNs) at high temperature and pressure [20-22]. Furthermore, the proportion of -CONH bond components for Pt/GNs (PAMAM) and Pt/GNs (CS) are $40.94 \%$ and $37.98 \%$, respectively, both are much higher than that for Pt/GNs, which may be due to that some of PAMAM and CS chains have been bonded to the graphene surface during the GO reduction process [21]. The $\mathrm{Pt} 4 \mathrm{f}$ spectrum of $\mathrm{Pt} / \mathrm{GNs}$ is displayed in Figure 1D. Based on curve fitting with a mixed Gaussian-Lorentzian line shape, $\mathrm{Pt}$ seems to exist in various states. The most intense doublet (71.19 eV and $74.66 \mathrm{eV}$ ) is ascribed to metallic $\mathrm{Pt}$ (0) [23]. The doublet (71.92 eV and $75.51 \mathrm{eV})$ can be assigned to $\mathrm{Pt}$ (II) chemical state $\left(\mathrm{PtO}\right.$ and $\left.\mathrm{Pt}(\mathrm{OH})_{2}\right)$ [24]. Correspondingly, $\mathrm{Pt} 4 \mathrm{f}$ of $\mathrm{Pt} / \mathrm{GNs}$ (CS) exhibits the clear peaks which can be deconvoluted to reveal $\mathrm{Pt}(0)$ species at $71.39 \mathrm{eV}$ and $74.85 \mathrm{eV}$ (Figure 1E). The peaks assigned to Pt (II) species are also observed at $72.17 \mathrm{eV} \& 76.14 \mathrm{eV}$. Similarly, $\mathrm{Pt}(0)$ species is the main species for $\mathrm{Pt}$ in $\mathrm{Pt} / \mathrm{GNs}$ (CS). As shown in Figure 1F, $\mathrm{Pt} 4 \mathrm{f}$ spectra of $\mathrm{Pt} / \mathrm{GNs}$ (PAMAM) show the presence of metallic $\mathrm{Pt}(0)(71.38 \mathrm{eV}, 74.84 \mathrm{eV}), \mathrm{PtO} / \mathrm{Pt}(\mathrm{OH})_{2}(72.4 \mathrm{eV}$, $77.71 \mathrm{eV}$ ), respectively. It is calculated that the percentages of $\mathrm{Pt}(0)$ for $\mathrm{Pt} / \mathrm{GNs}, \mathrm{Pt} / \mathrm{GNs}$ (CS), and $\mathrm{Pt} / \mathrm{GNs}$ (PAMAM) are $73.49 \%, 68.36 \%, 62.21 \%$, respectively, and the percentages of $\mathrm{Pt}$ (II) for Pt/GNs, $\mathrm{Pt} / \mathrm{GNs}$ (CS), and Pt/GNs (PAMAM) are 26.51\%, 31.64\%, 37.79\%, respectively. It is reported that the 
existence of appropriate amount of oxide species may promote methanol oxidation reaction in acid medium $[25,26]$. Furthermore, it can be seen that the binding energies of $\mathrm{Pt} 4 \mathrm{f} 7 / 2$ and $\mathrm{Pt} 4 \mathrm{f} 5 / 2$ for $\mathrm{Pt}$ (0) in Pt/GNs (PAMAM) and Pt/GNs (CS) shift to a higher value in comparison with that in Pt/GNs, indicating that $\mathrm{Pt} / \mathrm{GNs}$ (PAMAM) and $\mathrm{Pt} / \mathrm{GNs}$ (CS) have stronger interaction between $\mathrm{Pt}$ and GNs (support) due to the introduction of PAMAM and CS [27].
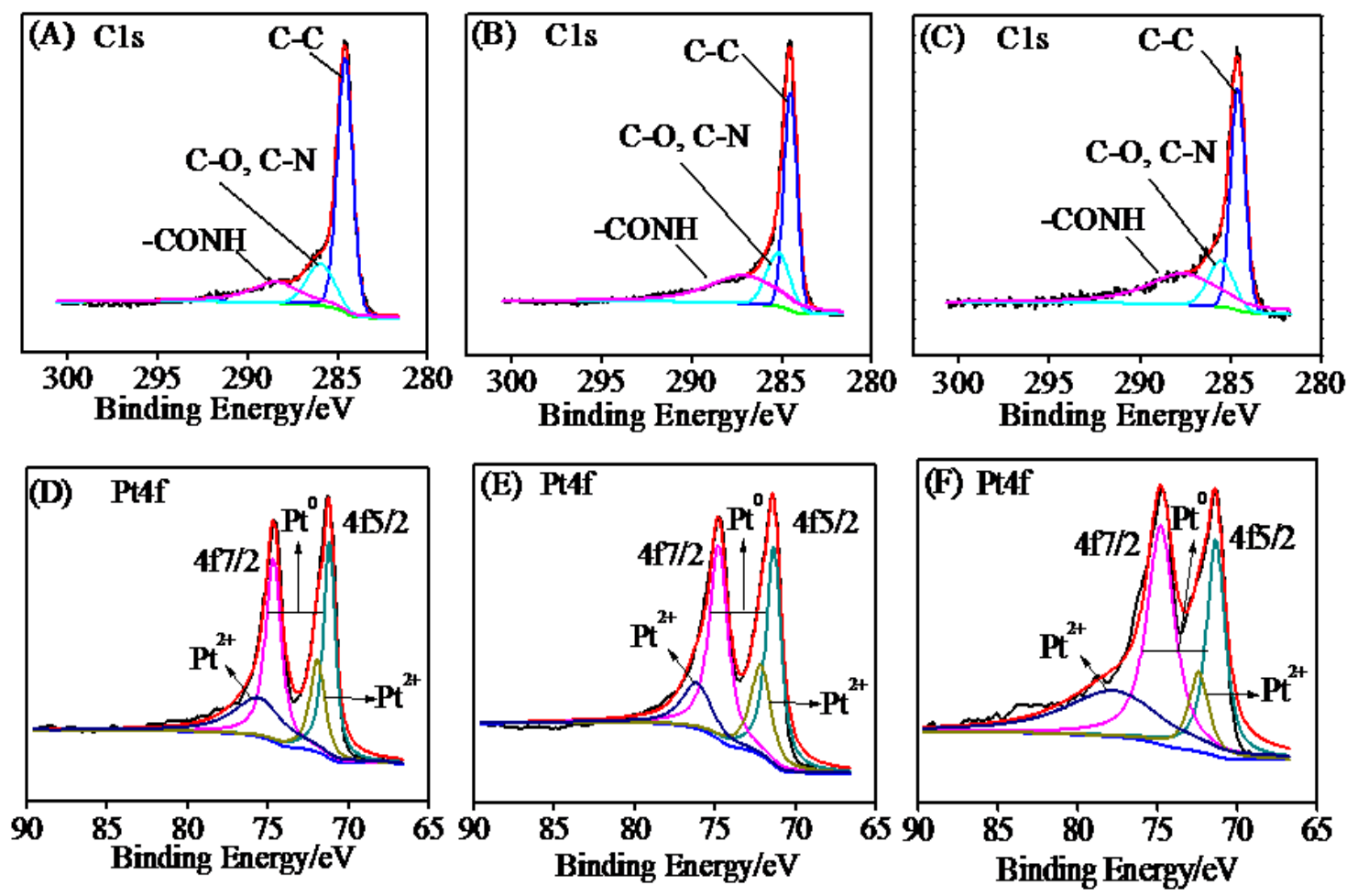

Figure 1. C1s XPS spectra of Pt/GNs (A); Pt/GNs (CS) (B); Pt/GNs (PAMAM-polyamidoamine) (C); $\mathrm{Pt} 4 \mathrm{f}$ XPS spectra of Pt/GNs (D); Pt/GNs (CS) (E); Pt/GNs (PAMAM) (F).

Transmission electron microscope (TEM) and high-resolution transmission electron microscope (HRTEM) images of Pt/GNs (PAMAM), Pt/GNs (CS), and Pt/GNs are shown in Figure 2. It is found that the Pt nanoparticles in Pt/GNs (PAMAM) were mainly in the form of flower-like clusters consisting of primary nanoparticles (Figure $2 \mathrm{~A}, \mathrm{~B}$ ), and the size of the primary particles were uniform, with the average diameter of about $5 \mathrm{~nm}$ as seen in the inset of Figure 2A. ThenHRTEM image in Figure $2 \mathrm{C}$ presents the details fringes of $\mathrm{Pt}$ for $\mathrm{Pt} / \mathrm{GNs}$ (PAMAM). The lattice fringes with a d-spacing of $0.226 \mathrm{~nm}$ is attributed to the spacing of the (111) planes in face-centered cubic (fcc) $\mathrm{Pt}[28,29]$, which further suggests the zero-valent state of Pt and high crystallinity of Pt nanoparticles. Figure 2D,E show the $\mathrm{Pt}$ nanoparticles of $\mathrm{Pt} / \mathrm{GNs}$ (CS) are highly dispersed on the surface of GNs, mainly in the form of spherical particles. As depicted in the inset of Figure 2D, the particle size of Pt nanoparticles was very uniform, with the average diameter of about $3 \mathrm{~nm}$. It should be noted that uniform and small spherical Pt nanoparticles have a significant advantage of large surface areas. Similarly, the HRTEM image in Figure 2F presents the details fringes of $\mathrm{Pt}$ for Pt/GNs (CS), and the lattice fringes with a d-spacing of $0.225 \mathrm{~nm}$ correspond to the (111) plane of fcc Pt. In contrast, Pt particles in Pt/GNs (Figure 2G-H) are big and non-uniform, with the average diameter about 10-34 $\mathrm{nm}$ (the inset of Figure 2G). Furthermore, the lattice spacing for dark Pt particles is $0.227 \mathrm{~nm}$ (Figure 2I). Obviously, the dispersity of $\mathrm{Pt}$ nanoparticles in $\mathrm{Pt} / \mathrm{GNs}$ (PAMAM) and Pt/GNs (CS) is drastically improved compared with $\mathrm{Pt} / \mathrm{GNs}$, and their morphologies can be effectively controlled by PAMAM and CS. 

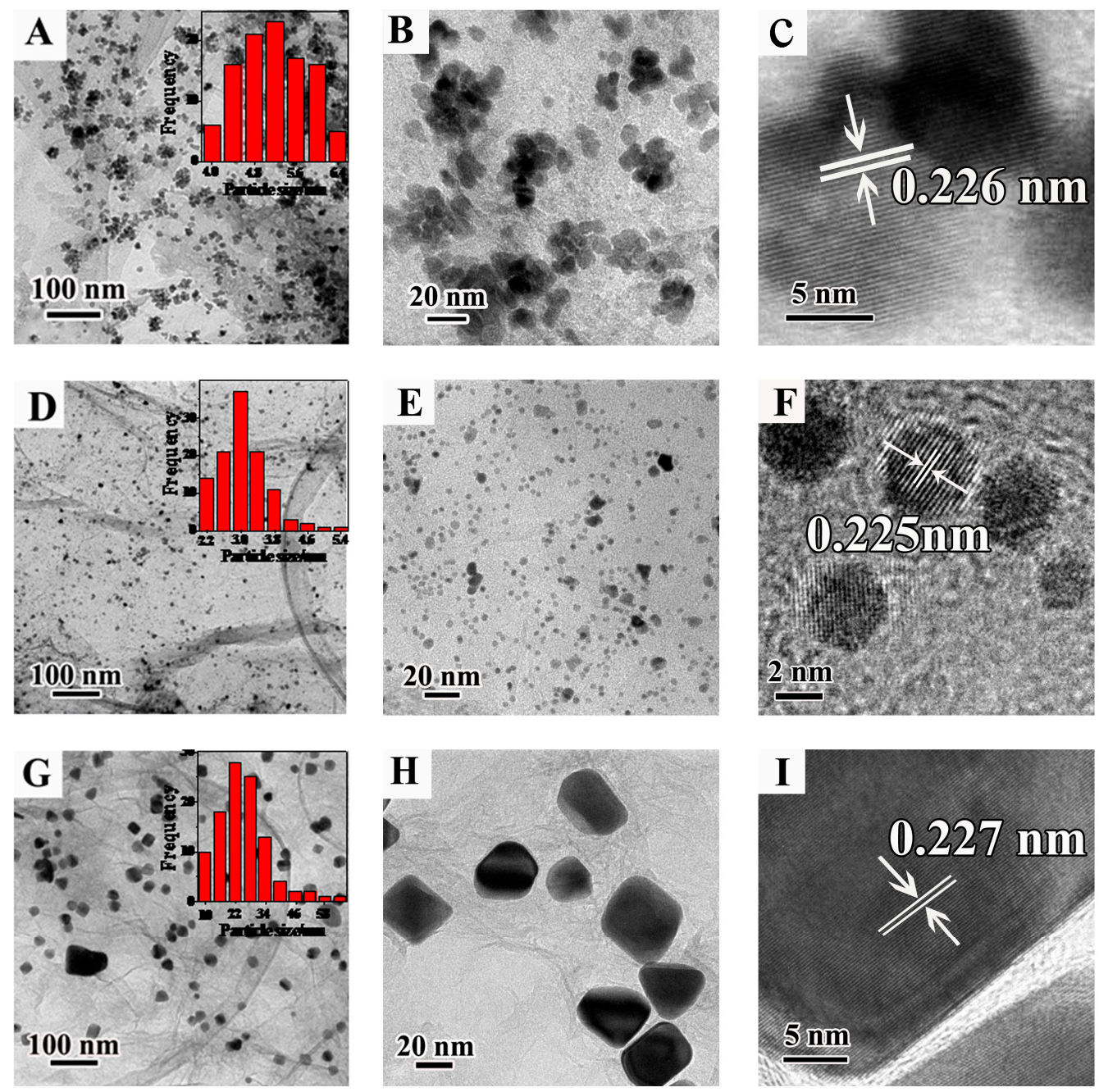

Figure 2. TEM images of Pt/GNs (PAMAM) (A,B); Pt/GNs (CS) (D,E); Pt/GNs (G,H). Size-distribution of Pt particles in Pt/GNs (PAMAM) (the inset of (A)); Pt/GNs (CS) (the inset of (D)); Pt/GNs (the inset of (G)). HRTEM images of Pt particles in Pt/GNs (PAMAM) (C); Pt/GNs (CS) (F); Pt/GNs (I).

The shape of Pt nanoparticles on Pt/GNs (PAMAM) is different from that of the Pt nanoparticles on Pt/GNs (CS). As for Pt/GNs (PAMAM), the primary Pt nanoparticles are formed with uniform size due to the mooring role of the protonated amines in PAMAM. Meanwhile, with the template effect of the dendrimer stucture, these primary nanoparticles are connected to each other to form flower-like nanoclusters. Similarly, CS also can be protonated under acidic conditions to greatly enhance the solubility of CS and promote polymer chain segment stretching in aqueous solution [16], which brings about the electrostatic interaction between $\mathrm{PtCl}_{4}{ }^{2-}$ and protonated $-\mathrm{NH}^{3+}$ in the polymer chain. The interaction contributes to the rapid nucleation of $\mathrm{Pt}$ particles after the reduction of $\mathrm{PtCl}_{4}{ }^{2-}$. The rich hydroxyls in CS act as a steric hindrance agent to protect Pt particles from further aggregation [30], resulting in the formation of uniform Pt nanoparticles. Saidi and Fichthorn have pointed out that both thermodynamics and kinetics likely played a role in the formation of these nanostructures [31,32]. On one hand, PAMAM (or CS) can induce kinetic Pt particles shapes by regulating the relative Pt fluxes to desired facets ( $\mathrm{Pt}$ (111) in this work) [32]. On the other hand, the freshly formed primary Pt particles are thermodynamically unstable because of their high surface energy, and they tend to aggregate driven by the minimization of interfacial energy [33,34]. With the template of the dendrimer structure, Pt primary particles on Pt/GNs (PAMAM) are inclined to aggregate into nanoclusters; on the contrary, the rich hydroxyls in CS block Pt primary particles surface diffusion, leading to uniform 
spherical particles. Additionally, it is reported that organic amines can serve as a reducing agent to reduce GO into GNs $[35,36]$. Therefore, PAMAM and CS should promote to reduce GO and $\mathrm{PtCl}_{4}{ }^{2-}$ into GNs and Pt under hydrothermal conditions, accelerating the nucleation rate of Pt particles and favoring the formation of Pt nanoparticles of smaller size. Thus, PAMAM and CS not only act as a template to control the morphology of Pt nanoparticles but also serve as an intrinsic reducing agent to increase the dispersity of Pt nanoparticles.

Powder X-ray diffraction (XRD) patterns of Pt/GNs, Pt/GNs (CS), and Pt/GNs (PAMAM) are

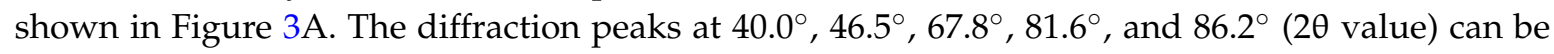
assigned to (111), (200), (220), (311), and (222) crystalline planes of Pt (0) fcc lattice, respectively [37], which further indicates good crystallinity and zero-valent state of $\mathrm{Pt}$ in the obtained three composites. The diffraction peak for $\mathrm{Pt}$ (220) is used to estimate the size of Pt nanoparticles with the Scherrer Equation (1) [30,37].

$$
d=K \lambda / \beta \cos \theta
$$

It is calculated that the average size of Pt nanoparticles in Pt/GN, Pt/GNs (CS) and Pt/GNs (PAMAM) is about 21.5, 4.0 and $5.5 \mathrm{~nm}$, respectively, which are consistent with the TEM analysis.
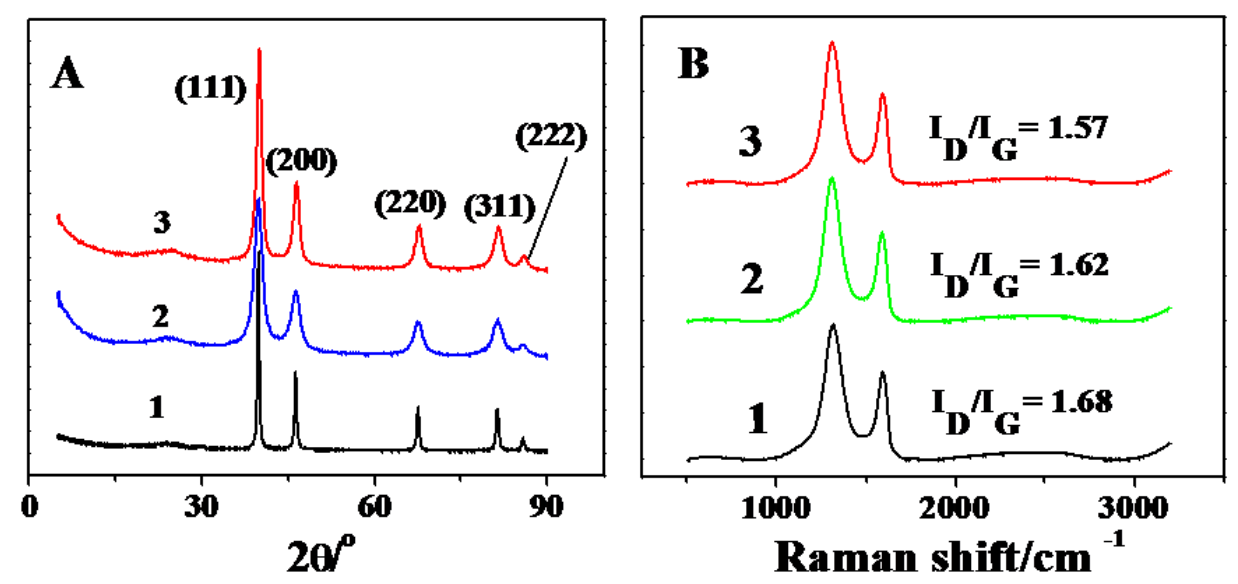

Figure 3. XRD patterns (A) and Raman spectra (B) of Pt/GNs (1), Pt/GNs (CS) (2), and $\mathrm{Pt} / \mathrm{GNs}(\mathrm{PAMAM})(3)$.

Figure 3B displays Raman spectra of Pt/GNs, Pt/GNs (CS), and Pt/GNs (PAMAM). The D band (about $1310 \mathrm{~cm}^{-1}$ ) originates from the defects in the curved graphene sheet and staging disorder, while the $\mathrm{G}$ band (about $1597 \mathrm{~cm}^{-1}$ ) was associated with the graphitic hexagonpinch mode [38,39]. The $I_{\mathrm{D}} / I_{\mathrm{G}}$ intensity ratio can be used to measure the crystalline quality of graphite or graphene via different kinds of treatment, increasing with the amount of disorder for grapheme-based materials [40-43]. It is found that the values of $I_{\mathrm{D}} / I_{\mathrm{G}}$ for Pt/GNs (PAMAM) and Pt/GNs (CS) are 1.57 and 1.62, both of which are lower than the value of $I_{\mathrm{D}} / I_{\mathrm{G}}$ for the $\mathrm{Pt} / \mathrm{GNs}$ value (1.68), indicating that the disorder degree of GNs is decreased in Pt/GNs (PAMAM) and Pt/GNs (CS). A possible reason for this is that PAMAM and CS promote GO to be reduced into GNs, in favor of the recovery of the original structure for GNs. GNs with lower degrees of disorder can maintain their good electron transfer capability and endow graphene-based composites with better catalytic performance [42,44].

\subsection{Electrocatalysis}

Figure 4 displays the cyclic voltammetry $(\mathrm{CV})$ curves of the different composites conducted at room temperature in $0.5 \mathrm{M} \mathrm{H}_{2} \mathrm{SO}_{4}$ solution at $100 \mathrm{mV} \cdot \mathrm{s}^{-1}$. For all composites, typical hydrogen adsorption/desorption peaks and Pt oxide formation/reduction peaks can be observed. Their electrochemical surface area (ECSA) is evaluated by the integrated charge $\left(Q_{\mathrm{H}}\right)$ in the hydrogen adsorption region, with Equation (2) [42]. 


$$
\mathrm{ECSA}=Q_{\mathrm{H}} /\left(210 \mathrm{uC} \cdot \mathrm{cm}^{-2} \times \mathrm{Pt} \text { loading }\right)
$$

By calculation, it is found that the specific ECSA of Pt/GNs (PAMAM) and Pt/GNs (CS) is $117.8 \mathrm{~m}^{2} \cdot \mathrm{g}^{-1}$ and $103.7 \mathrm{~m}^{2} \cdot \mathrm{g}^{-1}$, respectively, which is higher than that of Pt/GNs $\left(47.7 \mathrm{~m}^{2} \cdot \mathrm{g}^{-1}\right)$ and commercial catalyst Pt/C $\left(75.1 \mathrm{~m}^{2} \cdot \mathrm{g}^{-1}\right)$ (Table 1$)$. The higher ECSA of Pt/GNs (PAMAM) and Pt/GNs (CS) are obviously related to the unique morphology and uniform distribution of Pt nanoparticles, which is helpful to improve their catalytic performance [37].

Table 1. Electrochemical parameters of as-synthesized different composites ${ }^{\text {a }}$.

\begin{tabular}{cccc}
\hline Composites & $\begin{array}{c}\mathbf{E C S A} / \mathbf{m}^{\mathbf{2}} \cdot \mathbf{g}^{-\mathbf{1}} \\
\text { (Electrochemical } \\
\text { Surface Area) }\end{array}$ & Onset Potential $\mathbf{~} / \mathbf{V}$ & ${\text { Massactivity/mA } \mathbf{m} \mathbf{m}^{-\mathbf{1}}}$ \\
\hline $\mathrm{Pt} / \mathrm{C}-\mathrm{JM}$ & 75.1 & 0.45 & 455 \\
$\mathrm{Pt} / \mathrm{GNs}$ & 47.7 & 0.40 & 556 \\
$\mathrm{Pt} / \mathrm{GNs}(\mathrm{CS})$ & 117.8 & 0.36 & 1031 \\
$\mathrm{Pt} / \mathrm{GNs}$ (PAMAM- & 103.7 & 0.35 & 1203 \\
polyamidoamine) & & & \\
\hline
\end{tabular}

a The reproducibility of electrochemical experiment data in our work was ensured by repeated experiments, and their standard deviation is less than $3 \%$; ${ }^{b}$ The onset potential is defined as the potential at which $10 \%$ of the current value at the peak potential was reached in this work [34].
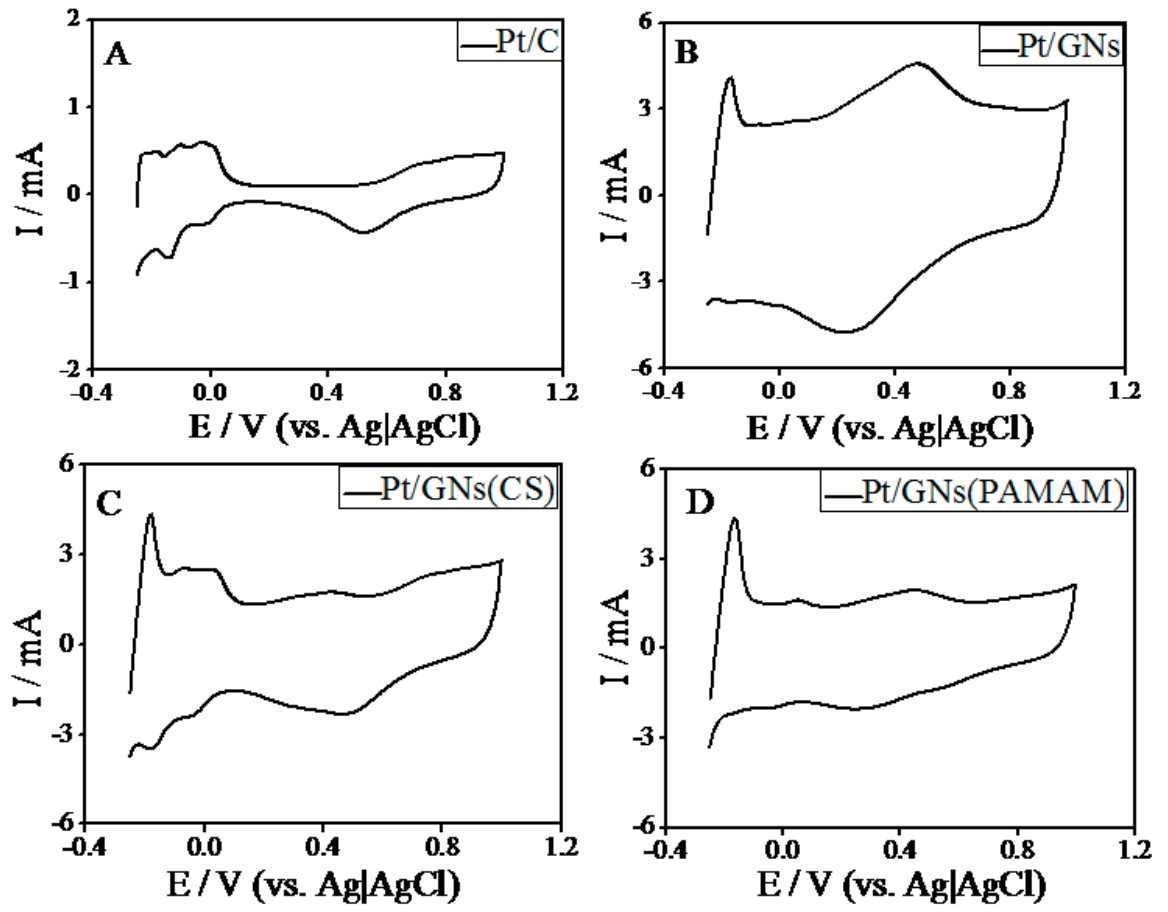

Figure 4. $\mathrm{CV}$ curves in $0.5 \mathrm{M} \mathrm{H}_{2} \mathrm{SO}_{4}$ at $100 \mathrm{mV} \cdot \mathrm{s}^{-1}$ : $\mathrm{Pt} / \mathrm{C}$ (A); Pt/GNs (B); Pt/GNs (CS) (C); Pt/GNs (PAMAM) (D).

The electrocatalytic activities of as-synthesized composites for MOR were discussed by analyzing their $\mathrm{CV}$ curves carried out in $0.5 \mathrm{M} \mathrm{H}_{2} \mathrm{SO}_{4}$ containing $1 \mathrm{M} \mathrm{CH}_{3} \mathrm{OH}$ solution at a scan rate of $100 \mathrm{mV} \cdot \mathrm{s}^{-1}$ (Figure 5A,B). It can be seen from Figure 5B that the Pt/GNs (CS) and Pt/GNs (PAMAM) exhibit a mass activity (forward peak current density) of $1031 \mathrm{~mA} \cdot \mathrm{mg}^{-1}$ and $1203 \mathrm{~mA} \cdot \mathrm{mg}^{-1}$ (listed in Table 1), which is 2.3 and 2.6 times higher than that of $\mathrm{Pt} / \mathrm{C}\left(455 \mathrm{~mA} \cdot \mathrm{mg}^{-1}\right)$, respectively. It is observed that the onset potential value for $\mathrm{Pt} / \mathrm{GNs}$ (CS) and $\mathrm{Pt} / \mathrm{GNs}$ (PAMAM) is 0.36 and $0.35 \mathrm{~V}$, respectively, which is lower than that for Pt/GNs $(0.40 \mathrm{~V})$ and $\mathrm{Pt} / \mathrm{C}(0.45 \mathrm{~V})$ (Table 1). Lower onset potential 
may contribute to superior electro-catalytic activity for methanol oxidation [37,45]. It is reported that the functional-modified graphene is in favor of inhibiting the irreversible aggregation process of $\mathrm{Pt}$ /graphene composites [46]. In this case, the introduction CS and PAMAM into the graphene layer may play a functional-modified role to prevent the aggregation of graphene composites, resulting in remarkably improved electrocatalytic activity.
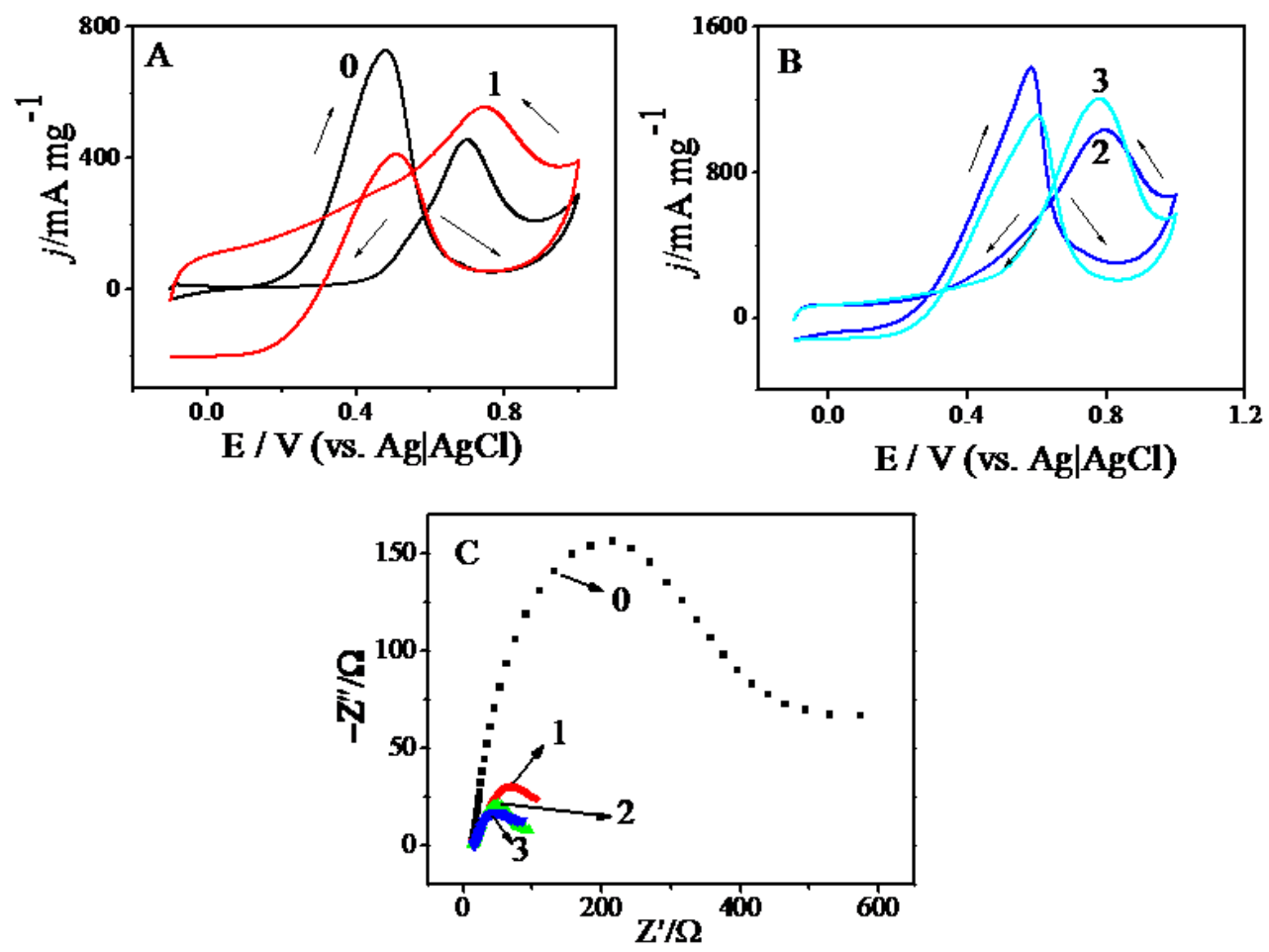

Figure 5. (A) $\mathrm{CV}$ curves in $1 \mathrm{M} \mathrm{CH}_{3} \mathrm{OH}+0.5 \mathrm{M} \mathrm{H}_{2} \mathrm{SO}_{4}$ at $100 \mathrm{mV} \cdot \mathrm{s}^{-1}$ : $\mathrm{Pt} / \mathrm{C}(\mathbf{0}), \mathrm{Pt} / \mathrm{GNs}$ (1); (B) CV curves in $1 \mathrm{M} \mathrm{CH}_{3} \mathrm{OH}+0.5 \mathrm{M} \mathrm{H}_{2} \mathrm{SO}_{4}$ at $100 \mathrm{mV} \cdot \mathrm{s}^{-1}$ : Pt/GNs (CS) (2), Pt/GNs (PAMAM) (3); (C) Nyquist plots of EIS for methanol electrooxidation in $1 \mathrm{M} \mathrm{CH}_{3} \mathrm{OH}+0.5 \mathrm{M} \mathrm{H}_{2} \mathrm{SO}_{4}$ solution: $\mathrm{Pt} / \mathrm{C}(\mathbf{0})$, Pt/GNs (1), Pt/GNs (CS) (2), Pt/GNs (PAMAM) (3).

In addition, the enhanced catalytic activity may be ascribed to the superior electric conductivities of the as-synthesized composites, which can be proven by EIS analysis. The Nyquist plots of EIS for Pt/GNs (PAMAM), $\mathrm{Pt} / \mathrm{GNs}$ (CS), $\mathrm{Pt} / \mathrm{GNs}$ and $\mathrm{Pt} / \mathrm{C}$ in $1 \mathrm{M} \mathrm{CH}_{3} \mathrm{OH}+0.5 \mathrm{M} \mathrm{H}_{2} \mathrm{SO}_{4}$ solution at $0.5 \mathrm{~V}$ are shown in Figure 5C. The diameter of semicircle at high frequencies is a measure of charge transfer resistance related to the charge transfer reaction kinetics [47-49]. Obviously, the diameters of semicircle for Pt/GNs (PAMAM) and Pt/GNs (CS) are much lower than those of Pt/GNs and Pt/C, which demonstrates that $\mathrm{Pt} / \mathrm{GNs}$ (PAMAM) and $\mathrm{Pt} / \mathrm{GNs}$ (CS) have lower charge transfer resistance and faster reaction rate for MOR [50]. This suggests that the introduction of PAMAM and CS can keep the good electron transfer capability of graphene-based composites to endow them with better catalytic performance.

In order to directly observe their anti-poisoning ability to CO-like intermediate species, $\mathrm{CO}$ stripping curves of $\mathrm{Pt} / \mathrm{GNs}$ (PAMAM), $\mathrm{Pt} / \mathrm{GNs}(\mathrm{CS}), \mathrm{Pt} / \mathrm{GNs}$ and $\mathrm{Pt} / \mathrm{C}$ were measured by oxidation of pre-adsorbed and saturated $\mathrm{CO}$ in the $0.5 \mathrm{M} \mathrm{H}_{2} \mathrm{SO}_{4}$ solution at $100 \mathrm{mV} \cdot \mathrm{s}^{-1}$ (Figure 6A). The peak potential of CO oxidation for Pt/GNs (PAMAM) (curve 3) and Pt/GNs (CS) (curve 2) is 0.59 and $0.64 \mathrm{~V}$, respectively, which is lower than that for $\mathrm{Pt} / \mathrm{GNs}(0.67 \mathrm{~V})$ and $\mathrm{Pt} / \mathrm{C}(0.72 \mathrm{~V})$. Their more negative $\mathrm{CO}$ oxidation peak demonstrates that $\mathrm{CO}$ on $\mathrm{Pt} / \mathrm{GNs}$ (PAMAM) and $\mathrm{Pt} / \mathrm{GNs}$ (CS) surface is easier to oxidize and remove from the Pt surface [27], suggesting an enhanced poisoning tolerance. The possible reasons for the greater tolerance to CO-like species are as follows: firstly, there are abundant cavities in the core of PAMAM and a large number of nitrogen-containing groups on the surface of PAMAM [51], 
and $\mathrm{CS}$ also possesses abundant $-\mathrm{NH}_{2}$ and $-\mathrm{OH}$ groups on its polymer chains [52], which results in a complex interaction between PAMAM (CS) mooring groups and Pt particles [30,53]. The strong interaction can induce modulation in the electronic structure of $\mathrm{Pt}$ particles and decrease the $\mathrm{Pt}-\mathrm{CO}$ binding energy to reduce the $\mathrm{CO}$ adsorption on $\mathrm{Pt}$ active sites $[9,12]$. This point can be proved by $\mathrm{Pt} 4 \mathrm{f}$ XPS spectra analysis. As shown in Figure 1D, the binding energy of $\mathrm{Pt} 4 \mathrm{f}$ for $\mathrm{Pt} / \mathrm{GNs}$ (PAMAM) and $\mathrm{Pt} / \mathrm{GNs}$ (CS) presents a positive shift due to the introduction of PAMAM and CS, which means that the interaction between $\mathrm{Pt}$ and support materials is much stronger than that of their corresponding counterpart Pt/GNs $[27,29]$. A higher binding energy would increase metal bond strength and reduce the potential of metal to form strong bonds with absorbed reactants, in favor of removing the strongly adsorbed CO-like species during MOR [29]. Secondly, the protonated $\mathrm{NH}_{3}{ }^{+}$groups or $-\mathrm{OH}$ groups can enhance the hydrophilic properties of RGO to promote water activation [16], and as a result, the adsorbed $\mathrm{OH}$ - species at the surface of Pt particles promote the oxidation of $\mathrm{CO}$ [30].

Chronoamperometry tests were carried out at $0.70 \mathrm{~V}$ for $3600 \mathrm{~s}$ to assess the electrocatalytic stability of different composites. As shown in Figure 6B, their current densities decay quickly during the initial minutes, which may be due to CO-like intermediate species poisoning on the Pt surface during the early stage of MOR [54]. Following this, the current densities decreased slowly and reach a quasi-stationary value after 3600 s. It was found that Pt/GNs (PAMAM) (curve 3) and Pt/GNs (CS) (curve 2) present the lower declining rate and the higher quasi-stationary current density in contrast with Pt/GNs (curve 1) and Pt/C (curve 0), suggesting an enhanced catalytic stability. The results are in agreement with CO stripping curves analysis. The superior catalytic activity and stability of $\mathrm{Pt} / \mathrm{GNs}$ (PAMAM) and Pt/GNs (CS) may be related to the fact that the abundant protonated $\mathrm{NH}_{3}{ }^{+}$groups or -OH groups can effectively stabilize $\mathrm{Pt}$ particles against gathering, endowing Pt active sites with a stronger ability to refresh $[16,30,51,53]$.
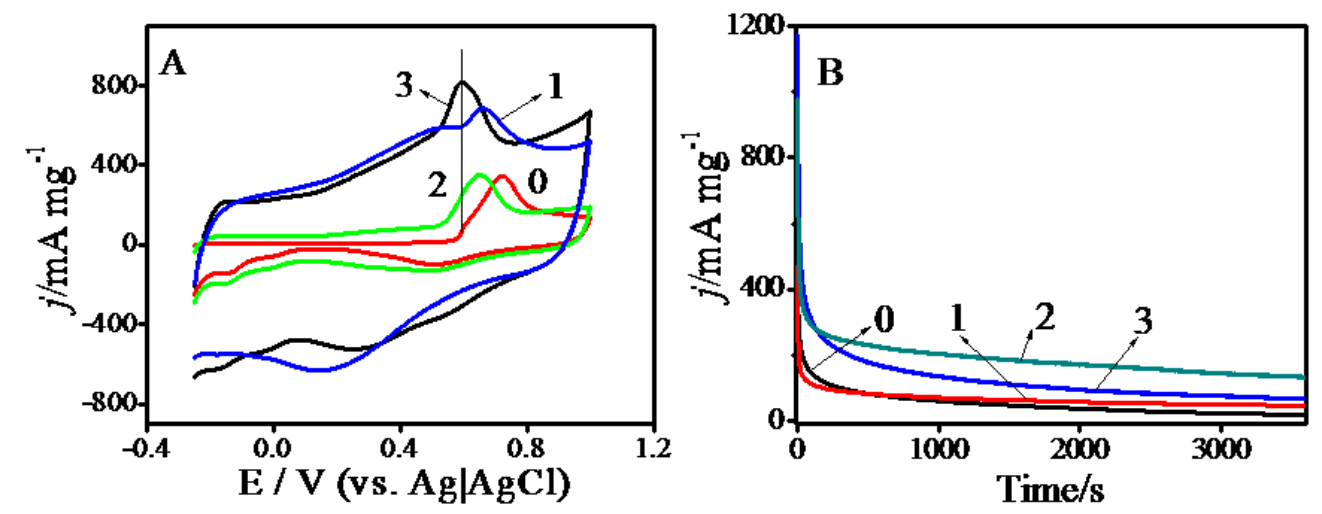

Figure 6. (A) CO-stripping voltammograms in $0.5 \mathrm{M} \mathrm{H}_{2} \mathrm{SO}_{4}$ : $\mathrm{Pt} / \mathrm{C}(\mathbf{0}), \mathrm{Pt} / \mathrm{GNs}$ (1), Pt/GNs (CS) (2), $\mathrm{Pt} / \mathrm{GNs}$ (PAMAM) (3); (B) Chronoamperometric curves in $1 \mathrm{M} \mathrm{CH}_{3} \mathrm{OH}+0.5 \mathrm{M} \mathrm{H}_{2} \mathrm{SO}_{4}$ : $\mathrm{Pt} / \mathrm{C}$ (0), $\mathrm{Pt} / \mathrm{GNs}$ (1), Pt/GNs (CS) (2), Pt/GNs (PAMAM) (3).

\section{Materials and Methods}

\subsection{Materials}

Natural graphite powder (about 325 mesh) was purchased from Alfa Aesar (Ward Hill, MA, USA). Commercial Pt/C catalyst (Hispec 3000, wt \% 20\%) was purchased from Johnson-Matthey (London, UK). Fourth generation amine-terminated polyamidoamine dendrimers (PAMAM) with the highest available purity (10 wt \% in methanol) were purchased from Sigma Aldrich (Darmstadt, Germany). Chitosan (CS) was purchased from Sinopharm Chemical Reagent Co. Ltd. (Shanghai, China), and then completely deacetylated as follows [55]: 80\% deacetylation CS was added to $50 \%$ $\mathrm{NaOH}$ solution and stirred for $6 \mathrm{~h}$ at $95^{\circ} \mathrm{C}$ under $\mathrm{N}_{2}$ protection. After that, the product was purified and lyophilized. Potassium chloride $(99 \%)$, hydrogen peroxide $(30 \%)$, potassium permanganate, 
potassium sulfate, concentrated sulfuric acid, phosphorus pentoxide, methanol, and ethanol were purchased from Sinopharm Chemical Reagent Co. Ltd. (Shanghai, China), and all the chemicals were of analytical grade. The water used in the experiments was distilled water.

\subsection{Synthesis of Pt/GNs (PAMAM) and Pt/GNs (CS)}

Graphene oxide (GO) was synthesized using a modified Hummers' method [56,57], and the detailed steps were described previously [5]. The overall synthetic route of Pt/GNs (PAMAM) and $\mathrm{Pt} / \mathrm{GNs}$ (CS) was illustrated in Scheme 1. In a typical procedure of Pt/GNs (PAMAM), $50 \mathrm{mg}$ of GO were dispersed in $25 \mathrm{~mL}$ of distilled water by sonication for $1 \mathrm{~h}$. Simultaneously, after removing methanol from $0.45 \mathrm{~mL} \mathrm{10 \%} \mathrm{PAMAM} \mathrm{methanol} \mathrm{solution,} \mathrm{PAMAM} \mathrm{was} \mathrm{dissolved} \mathrm{into} 20 \mathrm{~mL}$ water and its $\mathrm{pH}$ was adjusted to 3 with dilute hydrochloric acid. Then $5 \mathrm{~mL}$ of $\mathrm{K}_{2} \mathrm{PtCl}_{4}(1 \mathrm{~g} / 100 \mathrm{~mL})$ were added and stirring for $30 \mathrm{~min}$. After the completion of the stirring, the mixture was put into the GO solution and further sonicated for $1 \mathrm{~h}$ to ensure sufficient mixing, and its $\mathrm{pH}$ was adjusted to 3 again. Afterwards, the mixed suspension was transferred into a Teflon-lined stainless steel autoclave and reacted at $180^{\circ} \mathrm{C}$ for $12 \mathrm{~h}$ under autogenous pressure. When hydrothermal reaction was completed, autoclave was allowed to cool naturally to room temperature. Finally, the product was purified through repeated washing and centrifugation (at 10,000 rpm for $20 \mathrm{~min}$ ), then the black precipitate was lyophilized and Pt/GNs (PAMAM) were obtained. The Pt/GNs (CS) composite was synthesized by the same process, adjusting the $\mathrm{pH}$ of mixed solution to 3. For comparison, $\mathrm{Pt} / \mathrm{GNs}$ was synthesized by similar procedure without addition of PAMAM or CS. Pt actual contents in the composites were determined by ICP-AES (Thermo Scientific, Pleasanton, CA, USA) with the values of $31.42 \%$ for $\mathrm{Pt} / \mathrm{GNs}, 32.50 \%$ for Pt/GNs (CS) and 35.71\% for Pt/GNs (PAMAM), respectively.

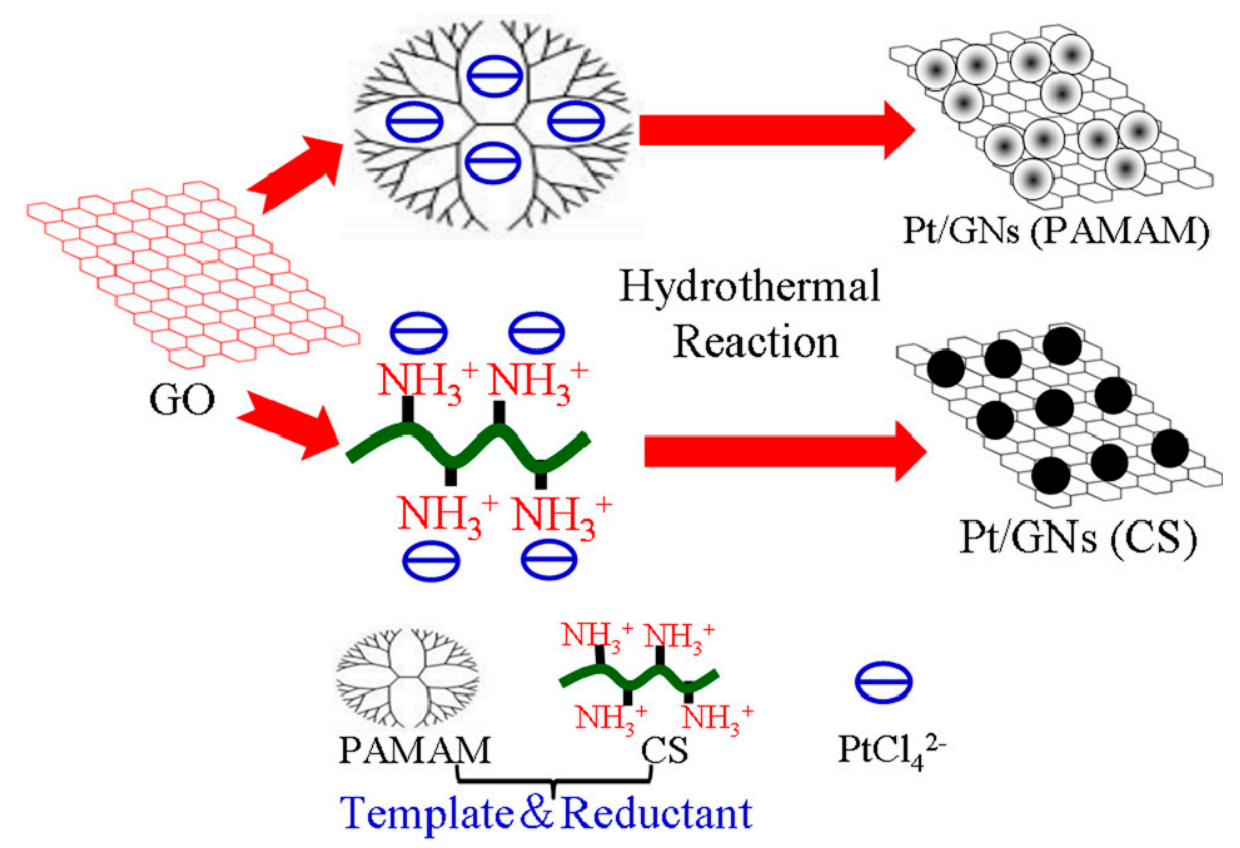

Scheme 1. The synthetic route of Pt/GNs (PAMAM) and Pt/GNs (CS) composites.

\subsection{Characterization}

The microscopic feature and morphology of the composites were characterized by a high-resolution transmission electron microscope (HRTEM, TECNAI G2, FEI, Hillsboro, OR, USA) operating at $200 \mathrm{~K}$. XPS was recorded on monochromatic Al Ka radiation $(1486.6 \mathrm{eV})$ using a Thermo Scientific VG ESCALAB 250 spectrometer (Thermo Scientific). XRD patterns were determined at a scanning rate of $5^{\circ} \cdot \mathrm{min}^{-1}$ on a Philips $X^{\prime}$ pert Pro diffractometer (PANalytical B.V., Holland, The Netherlands), using $\mathrm{Cu}$ Ka radiation. Raman spectra were measured through a Renishaw-invia Raman micro-spectrometer 
equipped with a $514 \mathrm{~nm}$ diode laser excitation on a 300 lines $\mathrm{mm}^{-1}$ grating. The amount of actual Pt loading was determined using inductively coupled plasma atomic emission spectroscopy (ICP-AES, ICAP6300).

\subsection{Electrochemical Measurements}

All electrochemical tests were performed with a standard three-electrode system on a CHI 660C electrochemical workstation (ChenHua, Shanghai, China) at room temperature. The three electrodes cell included an $\mathrm{Ag} / \mathrm{AgCl}$ (saturated $\mathrm{KCl}$ ) electrode as a reference electrode, a platinum column as a counter-electrode and a modified glassy carbon electrode as a working electrode. Its working electrode was modified as follows: $5 \mathrm{mg}$ of catalyst were ultrasonically dispersed into $1 \mathrm{~mL}$ ethanol to form homogeneous ink, then $5 \mu \mathrm{L}$ of ink were dropped onto the surface of pre-polished glass carbon electrode ( $3 \mathrm{~mm}$ in diameter). Subsequently, $7.5 \mu \mathrm{L}$ diluted $0.5 \%$ Nafion solution was dropped to fix the samples. Cyclic voltammetry $(\mathrm{CV})$ was tested in $0.5 \mathrm{M} \mathrm{H}_{2} \mathrm{SO}_{4}$ or $0.5 \mathrm{M} \mathrm{H}_{2} \mathrm{SO}_{4}+1.0 \mathrm{M} \mathrm{CH}_{3} \mathrm{OH}$ solution at room temperature with a scan rate of $100 \mathrm{mV} \cdot \mathrm{s}^{-1}$. The $\mathrm{CO}$ stripping voltammograms were recorded by oxidation of preadsorbed $\mathrm{CO}(\mathrm{COad})$ in $0.5 \mathrm{M} \mathrm{H}_{2} \mathrm{SO}_{4}$ solution at $100 \mathrm{mV} \cdot \mathrm{s}^{-1}$. CO gas was purged into $0.5 \mathrm{M} \mathrm{H}_{2} \mathrm{SO}_{4}$ solution at a constant potential of $0.1 \mathrm{~V}$ for $1800 \mathrm{~s}$ to ensure the complete adsorption of $\mathrm{CO}$ onto the samples. The excess $\mathrm{CO}$ in the electrolyte was driven out by purging $\mathrm{N}_{2}$ for $15 \mathrm{~min}$. Chronoamperometry was conducted at $0.70 \mathrm{~V}$ in a solution of $0.5 \mathrm{M} \mathrm{H}_{2} \mathrm{SO}_{4}+1.0 \mathrm{M} \mathrm{CH}_{3} \mathrm{OH}$ for a period of $3600 \mathrm{~s}$. Electrochemical impedance spectra (EIS) were performed in a solution containing $0.5 \mathrm{M} \mathrm{H}_{2} \mathrm{SO}_{4}$ and $1.0 \mathrm{M} \mathrm{CH}_{3} \mathrm{OH}$ at $25^{\circ} \mathrm{C}$. Its perturbation potential was $5 \mathrm{mV}$, and the frequency ranged from $0.01 \mathrm{~Hz}$ to $100 \mathrm{kHz}$.

\section{Conclusions}

In summary, a one-pot hydrothermal method was used to synthesize Pt/GNs (PAMAM) and $\mathrm{Pt} / \mathrm{GNs}$ (CS) composites. Under hydrothermal conditions, PAMAM and CS serve as templates to control the morphology of Pt particles, resulting in the formation of flower-like Pt nanoclusters for $\mathrm{Pt} / \mathrm{GNs}$ (PAMAM) and uniform spherical Pt nanoparticles for Pt/GNs (CS). Meanwhile, PAMAM and CS play a promotion role in the reduction process to accelerate the nucleation rate of $\mathrm{Pt}$ particles and lead to improved recovery of the $\mathrm{sp}^{2}$ bond for GNs. The controlled morphology of Pt nanoparticles on $\mathrm{Pt} / \mathrm{GNs}$ (PAMAM) and Pt/GNs (CS) is an important driving force to improve the performance of the catalysts. The introduction of PAMAM and CS results in stronger interaction between Pt and support materials and better electron transfer capability of grapheme-based composites, which synergistically contributes to the significantly improved catalytic activity (with values of $1031 \mathrm{~mA} \cdot \mathrm{mg}^{-1}$ and $1203 \mathrm{~mA} \cdot \mathrm{mg}^{-1}$ for Pt/GNs (CS) and Pt/GNs (PAMAM), respectively), stability and CO poisoning tolerance. The study above provides a green, simple and low-cost way to improve electrocatalytic performance and enhance the effective utilization of Pt catalysts in DMFC anodic reaction.

Acknowledgments: This work was financially supported by the National Natural Science Foundation of China (No. 21171037) and Research Foundation of the Education Department of Fujian Province (No. JA13082 \& No. JB13010).

Author Contributions: Zhongshui Li planned and designed the experiments. Yanli Wang performed the experimental works. Zhongshui $\mathrm{Li}$, Shuhong $\mathrm{Xu}$, and Fengling Lei contributed to the data analysis. Yanli Wang wrote the manuscript; Shen Lin supervised the project and revised manuscript; all authors discussed the results and approved of the final version of the manuscript.

Conflicts of Interest: The authors declare no conflict of interest.

\section{References}

1. Boppella, R.; Anjaneyulu, K.; Basak, P.; Manorama, S.V. Facile synthesis of face oriented ZnO crystals: Tunable polar facets and shape induced enhanced photocatalytic performance. J. Phys. Chem. C 2013, 117, 4597-4605. [CrossRef] 
2. Yu, C.L.; Yang, K.; Xie, Y.; Fan, Q.Z.; Yu, J.C.; Shu, Q.; Wang, C.Y. Novel hollow Pt-ZnO nanocomposite microspheres with hierarchical structure and enhanced photocatalytic activity and stability. Nanoscale 2013, 5, 2142-2151. [CrossRef] [PubMed]

3. Guo, W.; Zhang, F.; Lin, C.; Wang, Z.L. Direct growth of $\mathrm{TiO}_{2}$ nanosheet arrays on carbon fibers for highly efficient photocatalytic degradation of methyl orange. Adv. Mater. 2012, 24, 4761-4764. [CrossRef] [PubMed]

4. Yu, X.; Kuai, L.; Geng, B.Y. $\mathrm{CeO}_{2} / \mathrm{rGO} / \mathrm{Pt}$ sandwich nanostructure: rGO-enhanced electron transmission between metal oxide and metal nanoparticles for anodic methanol oxidation of direct methanol fuel cells. Nanoscale 2012, 4, 5738-5743. [CrossRef] [PubMed]

5. Lei, F.L.; Li, Z.S.; Ye, L.T.; Wang, Y.L.; Lin, S. One-pot synthesis of Pt/SnO $/ \mathrm{Sh}_{2} / \mathrm{G}$ s and its electro-photosynergistic catalysis for methanol oxidation. Int. J. Hydrog. Energy 2016, 41, 255-264. [CrossRef]

6. Li, F.M.; Gao, X.Q.; Xue, Q.; Li, S.N.; Chen, Y.; Lee, J.M. Reduced graphene oxide supported platinum nanocubes composites: One-pot hydrothermal synthesis and enhanced catalytic activity. Nanotechnology 2015, 26, 065603. [CrossRef] [PubMed]

7. Yun, S.; Lee, S.; Shin, C.; Park, S.; Kwon, S.J.; Park, H.S. One-pot self-assembled, reduced graphene oxide/palladium nanoparticle hybrid aerogels for electrocatalytic applications. Electrochim. Acta 2015, 180, 902-908. [CrossRef]

8. Alvarez, A.; Guzman, C.; Rivas, S.; Godinez, L.A.; Sacca, A.; Carbone, A.; Passalacqua, E.; Arriaga, L.G.; Ledesma-Garcia, J. Composites membranes based on nafion and PAMAM dendrimers for PEMFC applications. Int. J. Hydrog. Energy 2014, 39, 16686-16693. [CrossRef]

9. Maiyalagan, T. Pt-Ru nanoparticles supported PAMAM dendrimer functionalized carbon nanofiber composite catalysts and their application to methanol oxidation. J. Solid State Electrochem. 2009, 13, 1561-1566. [CrossRef]

10. Crespilho, F.N.; Huguenin, F.; Zucolotto, V.; Olivi, P.; Nart, F.C.; Oliveira, O.N. Dendrimers as nanoreactors to produce platinum nanoparticles embedded in layer-by-layer films for methanol-tolerant cathodes. Electrochem. Commun. 2006, 8, 348-352. [CrossRef]

11. Sun, L.S.; Ca, D.V.; Cox, J.A. Electrocatalysis of the hydrogen evolution reaction by nanocomposites of poly(amidoamine)-encapsulated platinum nanoparticles and phosphotungstic acid. J. Solid State Electrochem. 2005, 9, 816-822. [CrossRef]

12. Noroozifar, M.; Khorasani-Motlagh, M.; Ekrami-Kakhki, M.-S.; Khaleghian-Moghadam, R. Enhanced electrocatalytic properties of Pt-chitosan nanocomposite for direct methanol fuel cell by $\mathrm{LaFeO}_{3}$ and carbon nanotube. J. Power Sources 2014, 248, 130-139. [CrossRef]

13. Cogo, L.C.; Batisti, M.V.; Pereira-da-Silva, M.A.; Oliveira, O.N., Jr.; Nart, F.C.; Huguenin, F. Layer-by-layer films of chitosan, poly(vinyl sulfonic acid), and platinum for methanol electrooxidation and oxygen electroreduction. J. Power Sources 2006, 158, 160-163. [CrossRef]

14. Osifo, P.O.; Masala, A. The influence of chitosan membrane properties for direct methanol fuel cell applications. J. Fuel Cell Sci. Technol. 2011, 9, 011003. [CrossRef]

15. Pan, Y.; Bao, H.; Li, L. Noncovalently functionalized multiwalled carbon nanotubes by chitosan-grafted reduced graphene oxide and their synergistic reinforcing effects in chitosan films. ACS Appl. Mater. Interfaces 2011, 3, 4819-4830. [CrossRef] [PubMed]

16. Bao, H.; Pan, Y.; Ping, Y.; Sahoo, N.G.; Wu, T.; Li, L.; Li, J.; Gan, L.H. Chitosan-functionalized graphene oxide as a nanocarrier for drug and gene delivery. Small 2011, 7, 1569-1578. [CrossRef] [PubMed]

17. Li, Z.S.; Lei, F.L.; Ye, L.T.; Zhang, X.F.; Lin, S. Controlled synthesis of Pt/CS/PW12-GNs composite as an anodic electrocatalyst for direct methanol fuel cells. J. Nanopart. Res. 2015, 17, 192. [CrossRef]

18. Yu, D.; Dai, L. Self-assembled graphene/carbon nanotube hybrid films for supercapacitors. J. Phys. Chem. Lett. 2010, 1, 467-470. [CrossRef]

19. Wang, X.; Zhang, X.; He, X.; Ma, A.; Le, L.; Lin, S. Facile electrodeposition of flower-like PMo12-Pt/rGO composite with enhanced electrocatalytic activity towards methanol oxidation. Catalysts 2015, 5, 1275-1288. [CrossRef]

20. Huang, H.; Liu, Y.; Gao, Q.; Ruan, W.; Lin, X.; Li, X. Rational construction of strongly coupled metal-metal oxide-graphene nanostructure with excellent electrocatalytic activity and durability. ACS Appl. Mater. Interfaces 2014, 6, 10258-10264. [CrossRef] [PubMed] 
21. Li, Z.S.; Huang, X.M.; Zhang, X.F.; Zhang, L.; Lin, S. The synergistic effect of graphene and polyoxometalates enhanced electrocatalytic activities of Pt- $\left\{\mathrm{PEI}-\mathrm{GNs} /\left[\mathrm{PMo}_{12} \mathrm{O}^{40}\right]^{3-}\right\}_{n}$ composite films regarding methanol oxidation. J. Mater. Chem. 2012, 22, 23602-23607. [CrossRef]

22. Liu, X.; Du, H.; Sun, X.W. High-performance photoresponse of carbon-doped ZnO/reduced graphene oxide hybrid nanocomposites under UV and visible illumination. RSC Adv. 2014, 4, 5136-5140. [CrossRef]

23. You, H.J.; Zhang, F.L.; Liu, Z.; Fang, J.X. Free-standing Pt-Au hollow nanourchins with enhanced activity and stability for catalytic methanol oxidation. ACS Catal. 2014, 4, 2829-2835. [CrossRef]

24. Wang, H.; Wang, R.F.; Li, H.; Wang, Q.F.; Kang, J.A.; Lei, Z.Q. Facile synthesis of carbon-supported pseudo-core@shell PdCu@Pt nanoparticles for direct methanol fuel cells. Int. J. Hydrog. Energy 2011, 36, 839-848. [CrossRef]

25. Park, K.W.; Choi, J.H.; Kwon, B.K.; Lee, S.A.; Sung, Y.E.; Ha, H.Y.; Hong, S.A.; Kim, H.; Wieckowski, A. Chemical and electronic effects of $\mathrm{Ni}$ in $\mathrm{Pt} / \mathrm{Ni}$ and $\mathrm{Pt} / \mathrm{Ru} / \mathrm{Ni}$ alloy nanoparticles in methanol electrooxidation. J. Phys. Chem. B 2002, 106, 1869-1877. [CrossRef]

26. Biesinger, M.C.; Payne, B.P.; Grosvenor, A.P.; Lau, L.W.M.; Gerson, A.R.; Smart, R.S. Resolving surface chemical states in XPS analysis of first row transition metals, oxides and hydroxides: $\mathrm{Cr}, \mathrm{Mn}, \mathrm{Fe}, \mathrm{Co}$ and $\mathrm{Ni}$. Appl. Surf. Sci. 2011, 257, 2717-2730. [CrossRef]

27. Cui, Z.M.; Jiang, S.P.; Li, C.M. Highly dispersed MoOx on carbon nanotube as support for high performance Pt catalyst towards methanol oxidation. Chem. Commun. 2011, 47, 8418-8420. [CrossRef] [PubMed]

28. Huang, H.; Chen, Q.; He, M.; Sun, X.; Wang, X. A ternary Pt/ $\mathrm{MnO}_{2} /$ graphene nanohybrid with an ultrahigh electrocatalytic activity toward methanol oxidation. J. Power Sources 2013, 239, 189-195. [CrossRef]

29. Yu, S.; Liu, Q.; Yang, W.; Han, K.; Wang, Z.; Zhu, H. Graphene-CeO 2 hybrid support for Pt nanoparticles as potential electrocatalyst for direct methanol fuel cells. Electrochim. Acta 2013, 94, 245-251. [CrossRef]

30. Wietecha, M.S.; Zhu, J.; Gao, G.; Wang, N.; Feng, H.; Gorring, M.L.; Kasner, M.L.; Hou, S. Platinum nanoparticles anchored on chelating group-modified graphene for methanol oxidation. J. Power Sources 2012, 198, 30-35. [CrossRef]

31. Saidi, W.A.; Feng, H.J.; Fichthorn, K.A. Binding of polyvinylpyrrolidone to Ag surfaces: Insight into a structure-directing agent from dispersion-corrected density functional theory. J. Phys. Chem. C 2013, 117, 1163-1171. [CrossRef]

32. Al-Saidi, W.A.; Feng, H.J.; Fichthorn, K.A. Adsorption of polyvinylpyrrolidone on Ag surfaces: Insight into a structure-directing agent. Nano Lett. 2012, 12, 997-1001. [CrossRef] [PubMed]

33. Qi, X.; Balankura, T.; Zhou, Y.; Fichthorn, K.A. How structure-directing agents control nanocrystal shape: Polyvinylpyrrolidone-mediated growth of Ag nanocubes. Nano Lett. 2015, 15, 7711-7717. [CrossRef] [PubMed]

34. Li, Z.S.; Zhang, L.; Huang, X.M.; Ye, L.T.; Lin, S. Shape-controlled synthesis of Pt nanoparticles via integration of graphene and beta-cyclodextrin and using as a noval electrocatalyst for methanol oxidation. Electrochim. Acta 2014, 121, 215-222. [CrossRef]

35. Wu, T.; Wang, X.; Qiu, H.; Gao, J.; Wang, W.; Liu, Y. Graphene oxide reduced and modified by soft nanoparticles and its catalysis of the Knoevenagel condensation. J. Mater. Chem. 2012, 22, 4772-4779. [CrossRef]

36. Kim, N.H.; Kuila, T.; Lee, J.H. Simultaneous reduction, functionalization and stitching of graphene oxide with ethylenediamine for composites application. J. Mater. Chem. A 2013, 1, 1349-1358. [CrossRef]

37. Qiu, J.-D.; Wang, G.-C.; Liang, R.-P.; Xia, X.-H.; Yu, H.-W. Controllable deposition of platinum nanoparticles on graphene as an electrocatalyst for direct methanol fuel cells. J. Phys. Chem. C 2011, 115, 15639-15645. [CrossRef]

38. Guo, Q.; Zheng, Z.; Gao, H.L.; Ma, J.; Qin, X. $\mathrm{SnO}_{2}$ /graphene composite as highly reversible anode materials for lithium ion batteries. J. Power Sources 2013, 240, 149-154. [CrossRef]

39. Estudillo-Wong, L.A.; Vargas-Gomez, A.M.; Arce-Estrada, E.M.; Manzo-Robledo, A. TiO 2 /c composite as a support for Pd-nanoparticles toward the electrocatalytic oxidation of methanol in alkaline media. Electrochim. Acta 2013, 112, 164-170. [CrossRef]

40. Zhang, M.; Xie, J.; Sun, Q.; Yan, Z.; Chen, M.; Jing, J. Enhanced electrocatalytic activity of high Pt-loadings on surface functionalized graphene nanosheets for methanol oxidation. Int. J. Hydrog. Energy 2013, 38, 16402-16409. [CrossRef]

41. Zhong, X.; Wang, Z.; Huang, Y.; Yu, Y.; Feng, Q.; Li, Q. Fabrication of Pt nanoparticles on ethylene diamine functionalized graphene for formic acid electrooxidation. Int. J. Hydrog. Energy 2014, 39, 15920-15927. [CrossRef] 
42. Luo, Z.; Yuwen, L.; Bao, B.; Tian, J.; Zhu, X.; Weng, L.; Wang, L. One-pot, low-temperature synthesis of branched platinum nanowires/reduced graphene oxide (BPtNW/RGO) hybrids for fuel cells. J. Mater. Chem. 2012, 22, 7791-7796. [CrossRef]

43. Liu, R.; Li, S.; Yu, X.; Zhang, G.; Zhang, S.; Yao, J.; Keita, B.; Nadjo, L.; Zhi, L. Facile synthesis of Au-nanoparticle/polyoxometalate/graphene tricomponent nanohybrids: An enzyme-free electrochemical biosensor for hydrogen peroxide. Small 2012, 8, 1398-1406. [CrossRef] [PubMed]

44. Shi, J.-J.; Yang, G.-H.; Zhu, J.-J. Sonoelectrochemical fabrication of PDDA-RGO-PdPt nanocomposites as electrocatalyst for DAFCs. J. Mater. Chem. 2011, 21, 7343-7349. [CrossRef]

45. Luo, B.; Yan, X.; Xu, S.; Xue, Q. Polyelectrolyte functionalization of graphene nanosheets as support for platinum nanoparticles and their applications to methanol oxidation. Electrochim. Acta 2012, 59, 429-434. [CrossRef]

46. Mayavan, S.; Jang, H.-S.; Lee, M.-J.; Choi, S.H.; Choi, S.-M. Enhancing the catalytic activity of Pt nanoparticles using poly sodium styrene sulfonate stabilized graphene supports for methanol oxidation. J. Mater. Chem. A 2013, 1, 3489-3494. [CrossRef]

47. Cui, X.; Wu, S.N.; Jungwirth, S.; Chen, Z.B.; Wang, Z.H.; Wang, L.; Li, Y.X. The deposition of Au-Pt core-shell nanoparticles on reduced graphene oxide and their catalytic activity. Nanotechnology 2013, 24, 295402. [CrossRef] [PubMed]

48. Xiang, D.; Yin, L. Well-dispersed and size-tuned bimetallic $\mathrm{PtFe}_{x}$ nanoparticle catalysts supported on ordered mesoporous carbon for enhanced electrocatalytic activity in direct methanol fuel cells. J. Mater. Chem. 2012, 22, 9584-9593. [CrossRef]

49. Yang, S.D.; Shen, C.M.; Lu, X.J.; Tong, H.; Zhu, J.J.; Zhang, X.G.; Gao, H.J. Preparation and electrochemistry of graphene nanosheets-multiwalled carbon nanotubes hybrid nanomaterials as Pd electrocatalyst support for formic acid oxidation. Electrochim. Acta 2012, 62, 242-249. [CrossRef]

50. Huang, H.; Chen, H.; Sun, D.; Wang, X. Graphene nanoplate-Pt composite as a high performance electrocatalyst for direct methanol fuel cells. J. Power Sources 2012, 204, 46-52. [CrossRef]

51. Qian, L.; Yang, X. Dendrimer films as matrices for electrochemical fabrication of novel gold/palladium bimetallic nanostructures. Talanta 2008, 74, 1649-1653. [CrossRef] [PubMed]

52. Guo, W.; Xu, L.; Li, F.; Xu, B.; Yang, Y.; Liu, S.; Sun, Z. Chitosan-assisted fabrication and electrocatalytic activity of the composite film electrode of heteropolytungstate/carbon nanotubes. Electrochim. Acta 2010, 55, 1523-1527. [CrossRef]

53. Qian, L.; Yang, X. Polyamidoamine dendrimers-assisted electrodeposition of gold-platinum bimetallic nanoflowers. J. Phys. Chem. B 2006, 110, 16672-16678. [CrossRef] [PubMed]

54. Guo, S.; Dong, S.; Wang, E. Three-dimensional Pt-on-Pd bimetallic nanodendrites supported on graphene nanosheet: Facile synthesis and used as an advanced nanoelectrocatalyst for methanol oxidation. ACS Nano 2010, 4, 547-555. [CrossRef] [PubMed]

55. Wu, Z.; Feng, W.; Feng, Y.; Liu, Q.; Xu, X.; Sekino, T.; Fujii, A.; Ozaki, M. Preparation and characterization of chitosan-grafted multiwalled carbon nanotubes and their electrochemical properties. Carbon 2007, 45, 1212-1218. [CrossRef]

56. Kovtyukhova, N.I.; Ollivier, P.J.; Martin, B.R.; Mallouk, T.E.; Chizhik, S.A.; Buzaneva, E.V.; Gorchinskiy, A.D. Layer-by-layer assembly of ultrathin composite films from micron-sized graphite oxide sheets and polycations. Chem. Mater. 1999, 11, 771-778. [CrossRef]

57. Zeng, Q.O.; Cheng, J.S.; Tang, L.H.; Liu, X.F.; Liu, Y.Z.; Li, J.H.; Jiang, J.H. Self-assembled graphene-enzyme hierarchical nanostructures for electrochemical biosensing. Adv. Funct. Mater. 2010, 20, 3366-3372. [CrossRef]

(c) 2016 by the authors; licensee MDPI, Basel, Switzerland. This article is an open access article distributed under the terms and conditions of the Creative Commons Attribution (CC-BY) license (http://creativecommons.org/licenses/by/4.0/). 